\title{
Identification of mesenchymal stem cells and osteogenic factors in bone marrow aspirate and peripheral blood for spinal fusion by flow cytometry and proteomic analysis
}

\author{
Chi-Chien Niu ${ }^{1,5+}$, Song-Shu Lin ${ }^{1,2 \dagger}$, Li-Jen Yuan ${ }^{1,5}$, Lih-Huei Chen ${ }^{1,5}$, Tai-Long Pan ${ }^{3,4}$, Chuen-Yung Yang ${ }^{1,5}$,
} Po-Liang Lai ${ }^{1,5}$ and Wen-Jer Chen ${ }^{1,5^{*}}$

\begin{abstract}
Background: An in vivo animal study and a prospective clinical study have indicated that bone marrow aspirate (BMA) augments spinal arthrodesis. However, there is no quantified data to explain why fusion rate can be augmented by BMA in lumbar posterolateral fusion.

Methods: To analyze the proportion of mesenchymal stem cells (MSCs) and osteogenic factors in human BMA and peripheral blood (PB) of the same patient. Autologous BMA and PB from the patients were analyzed by flow cytometry (FACS) using cell markers for MSCs. The osteogenic potential of MSCs was determined by alkaline phosphatase (ALP) activity and calcium level quantification. Proteomics were used for the qualitative and quantitative mapping of the whole proteome from BMA and PB plasma. The mass-to-charge ratio was calculated by time-of-flight mass spectrometry (TOF-MS). The overexpression of protein was confirmed using Western blot analysis.

Results: The proportion of MSCs $\left(\mathrm{CD}_{3} 4^{-} / \mathrm{CD}_{2} 9^{+} / \mathrm{CD}_{105}{ }^{+}\right)$was higher in the BMA than that in the PB. Colony-forming cell (CFC) assays suggested that fewer colonies were formed in PB cultures than in BMA culture. There was no significant difference in the osteogenic potential of the MSCs between the PB and BMA. Proteomic mass spectrometry assays suggested that the levels of catalase (osteoclast inhibitor) and glutathione peroxidase 3 (osteogenic biomarker) were higher in the BMA than those in the PB, and this was confirmed by Western blot analysis.
\end{abstract}

Conclusions: The proportions of MSCs and osteogenic factors were higher in the BMA than in the PB. This may explain why fusion rate can be augmented by BMA in lumbar posterolateral fusion.

Keywords: Bone marrow aspirate, Mesenchymal stem cells, Flow cytometry, Proteomics, Lumbar posterolateral fusion

\section{Background}

Thus far, autologous bone graft is the gold standard for spinal fusion. Autologous cancellous bone harvested from the ilium is commonly used in intertransverse fusion of the lumbar spine. However, the incidence of complications associated with harvesting bone from the posterior iliac crest is significant. Various graft substitutes or autograft extenders have become available or

\footnotetext{
* Correspondence: chenwenj@adm.cgmh.org.tw

${ }^{\dagger}$ Equal contributors

'Department of Orthopaedic Surgery, Chang Gung Memorial Hospital, No 5, Fu-Hsing Street 333, Taoyuan, Kweishan, Taiwan

${ }^{5}$ College of Medicine, Chang Gung University, Taoyuan, Taiwan

Full list of author information is available at the end of the article
}

are currently under development including allografts $[1,2]$, ceramics $[3,4]$, demineralized bone matrix (DBM) [5,6], and cultured stem cells [7]. Some of these substitutes function as osteoconductors or as osteoinductors in the process of osteogenesis.

Bone marrow aspirate (BMA) is harvested percutaneously from a cancellous-rich site such as the iliac crest, proximal tibia, or calcaneus utilizing a bone marrow needle and large-gauge syringe. Animal studies have proven that BMA exhibits osteopromotive properties that promote spinal fusion due to the presence of osteoprogenitor cells and BMPs $[8,9]$. Our previous prospective clinical study indicated that BMA augments spinal arthrodesis [10].

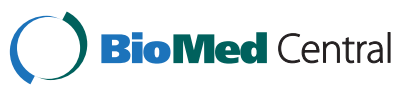

(c) 2014 Niu et al.; licensee BioMed Central Ltd. This is an Open Access article distributed under the terms of the Creative Commons Attribution License (http://creativecommons.org/licenses/by/4.0), which permits unrestricted use, distribution, and reproduction in any medium, provided the original work is properly credited. The Creative Commons Public Domain Dedication waiver (http://creativecommons.org/publicdomain/zero/1.0/) applies to the data made available in this article, unless otherwise stated. 
However, there is no quantified information available in the literature.

Mesenchymal stem cells (MSCs) exhibit multipotent differentiation potential, and have been shown to give rise to different mesodermal cell lineages including osteoblasts, chondroblasts, and adipocytes [11]. MSCs have to be plastic-adherent when maintained under standard culture conditions. MSCs express CD73, CD90, and CD105 and lack expression of the hematopoietic lineage markers c-kit, CD14, CD11b, CD34, CD45, CD19, CD79 $\alpha$, and human leukocyte antigen (HLA)-DR [12]. The aim of this study was to analyze the proportion of MSCs in human BMA. These factors in the PB of the same patient were also evaluated and compared with the BMA.

Human plasma is easily obtainable and clinically valuable [13]. Plasma components derived from tissues and organs vary in concentration by at least nine to ten orders of magnitude [14]. Two-dimensional gel electrophoresis (2-DE) is a reliable method to quickly resolve small quantities of proteins into hundreds of protein spots with definite molecular weights and pIs, and can allow for the comparison of protein intensity between samples. With the help of MALDI-TOF MS for rapid protein identification, qualitative and quantitative changes of primary gene products and post-translational modifications (PTMs) can be monitored $[15,16]$. For an identified osteogenic marker to be clinically useful, it should be measurable in body fluid samples.

In this study, we analyzed the proportion of MSCs, fibroblast colony-forming units (CFU-F) assay, and the osteogenic potential of MSCs and investigated the differences between human BMA and PB. Proteomic analysis was used to identify the proteins differently expressed in BMA compared to $\mathrm{PB}$ and the findings were confirmed by Western blotting. These findings may explain why fusion rate can be augmented by BMA in lumbar posterolateral fusion.

\section{Materials and methods}

We harvested the bone marrow aspirate (BMA) and peripheral blood $(\mathrm{PB})$ from 14 patients $(64.1 \pm 9.9$ years old $)$ who received total discectomy and posterior lumbar interbody fusion with cages. A study design table is shown in Table 1. The experimental protocol was approved by the Human Subjects Institutional Review Board at the Chang Gung Memorial Hospital.

\section{Surgical procedures}

During the operation, the patients were put in a prone position over the four-poster frame. The skin, overlying fascia, and musculature were opened to explore the posterior elements of the lumbosacral spine and the extent of the wound depending on the number of the levels of stenosis and instability was treated. After finishing the
Table 1 Study design table

\begin{tabular}{lccc}
\hline Method & $\begin{array}{c}\text { BMA sample } \\
\text { number }\end{array}$ & $\begin{array}{c}\text { PB sample } \\
\text { number }\end{array}$ & Patient ID \\
\hline Flow cytometry analysis & 4 & 4 & P1-P4 \\
CFU assay & 4 & 4 & P1-P4 \\
ALP activity measurement & 3 & 3 & P5-P7 \\
Calcium level quantification & 3 & 3 & P5-P7 \\
Mass spectrometric analysis & 3 & 3 & P8-P10 \\
Western blot analysis & 6 & 6 & P9-P14 \\
\hline
\end{tabular}

posterior lumbosacral decompression procedure, the right iliac crest close to the posterior superior iliac spine was explored. The outer cortex was exposed by subperiosteal dissection and a $3 \times 3-\mathrm{cm}$ hole was created by osteotomy. During bone graft harvesting, $10 \mathrm{ml}$ of BMA was aspirated and collected in a heparin-rinsed syringe.

\section{Flow cytometry analysis for phenotyping of MSCs}

Under sterile conditions, $1 \mathrm{ml}$ of BMA or PB was collected into a heparin-rinsed syringe. Two $\mathrm{ml}$ of $1 \mathrm{X} \mathrm{BD}$ Pharm Lyse ${ }^{\text {тм }}$ lysing solution (Becton Dickinson, Franklin Lakes, NJ, USA) was then added to each tube containing up to $200 \mu \mathrm{l}$ of a whole blood plus anti-CD29 FITCconjugated, anti-CD34 RPE conjugated and anti-CD105 Alexa Fluro-conjugated Ab (AbD Serotec, Oxford, UK) mixture and incubated at room temperature, protected from light, for $15 \mathrm{~min}$. Cell suspensions were washed, centrifuged, suspended, and analyzed on a FACS Calibur flow cytometer with CellQuest software (Becton Dickinson).

\section{Isolation of MSCs from BMA and peripheral blood}

Under sterile conditions, $10 \mathrm{ml}$ of BMA or $\mathrm{PB}$ was collected into a heparin-rinsed syringe. The sample was washed with PBS. Cells were recovered after centrifugation at $600 \mathrm{~g}$ for $10 \mathrm{~min}$. Up to $2 \times 10^{8}$ of nucleated cells in $5 \mathrm{ml}$ of DPBS were loaded onto $25 \mathrm{ml}$ of Percoll cushion (Pharmacia Biotech, Piscataway, NJ, USA) of a density of $1.073 \mathrm{~g} / \mathrm{ml}$ in a 50-ml conical tube. Cell separation was accomplished by centrifugation at 1,100 g for $40 \mathrm{~min}$ at $20^{\circ} \mathrm{C}$. The nucleated cells were collected from the interface, diluted with two volumes of PBS, and collected by centrifugation. The cells were then re-suspended, counted, and plated at $10^{5}$ cells in T-75 flasks (Coring, MA, USA). The cells were maintained in complete medium (DMEM-low glucose) (Gibco, Gran Island, NY, USA) containing $10 \%$ fetal bovine serum (FBS) and antibiotics (mixture of 100 units $/ \mathrm{ml}$ of penicillin and $100 \mu \mathrm{g} / \mathrm{ml}$ of streptomycin) (Gibco) at $37^{\circ} \mathrm{C}$ in a humidified atmosphere of $5 \% \mathrm{CO}_{2}$ and $95 \%$ air. After 4 days of primary culture, the non-adherent cells were removed by changing the medium. The medium was changed every 3 days thereafter. MSCs grow as symmetrical colonies and were subcultured at 10 to 14 days. 


\section{Colony-forming units (CFU-F) assay}

After the BMA or PB was enriched with Percoll [11], $10^{7}$ mononuclear cells were plated in a $100-\mathrm{mm}$ dish, cultured for 2 weeks at $37^{\circ} \mathrm{C}$ in $5 \%$ humidified $\mathrm{CO}_{2}$ atmosphere, fixed with methanol at $-20^{\circ} \mathrm{C}$ for $5 \mathrm{~min}$, and finally stained with Giemsa for counting. The number of colonies was determined by image analysis of each dish with Imagine-Pro version 5 software (Media Cybernetics, Rockville, MD, USA).

\section{Alkaline phosphatase (ALP) activity measurement} MSCs from $\mathrm{PB}$ or BMA were cultured in complete medium or induction medium (consisting of complete medium supplemented with $10^{-9} \mathrm{M}$ dexamethasone $20 \mathrm{mM} \beta$-glycerol phosphate and $50 \mu \mathrm{g} / \mathrm{ml}$ ascorbate-2phosphate) to measure the activity of ALP activity. At 4, 8,12 , and 16 days after culture, the culture medium was withdrawn and the dish was washed twice with $10 \mathrm{ml}$ of Tyrode's balanced salt solution. A 10-ml aliquot of ALP substrate buffer ( $50 \mathrm{mM}$ glycine, $1 \mathrm{mM} \mathrm{MgCl} 2$, $\mathrm{pH}$ 10.5), containing the soluble chromogenic ALP substrate (2.5 $\mathrm{mM} p$-nitrophenyl phosphate), was added at room temperature. During incubation, cell-surface ALP converts $p$-nitrophenyl phosphate into $p$-nitrophenol and changes to a yellowish color. Twenty minutes after addition of the substrate, $1 \mathrm{ml}$ of the buffer was removed from the culture and mixed with $1 \mathrm{ml}$ of $1 \mathrm{~N} \mathrm{NaOH}$ to stop the reaction. The absorbance of the mixture was read in triplicate on an ELISA MRX plate reader (Dynatech Labs, USA) at $405 \mathrm{~nm}$. The DNA content was determined by DNAzol reagent (Invitrogen, Carlsbad, CA, USA) according to the manufacturer's instructions. Enzyme activity was expressed as nmol $p$-nitrophenol/ $\min / \mu \mathrm{g}$ DNA.

\section{Calcium level quantification}

MSCs from $\mathrm{PB}$ or BMA were cultured in induction medium for 21 days. The culture dishes were rinsed twice with Tyrode's balanced salt solution and then poured into a $50-\mathrm{ml}$ tube containing $10 \mathrm{ml}$ of $0.5 \mathrm{~N}$ $\mathrm{HCl}$. Calcium was extracted from the cells by shaking for $24 \mathrm{~h}$ at $4^{\circ} \mathrm{C}$. Cellular debris was centrifuged and the calcium in the supernatant was measured quantitatively by a QuantiChrom ${ }^{\mathrm{Tw}}$ calcium assay kit (BioAssay Systems, Hayward, CA, USA) according to the manufacture'st instruction. Absorbance of the samples was measured on a MRX multiplate reader (Dynatech Labs, USA) at $570 \mathrm{~nm}$ for 5 to $10 \mathrm{~min}$ after the addition of the pertinent reagents. DNA content was determined by DNAzol reagent (Invitrogen) according to the manufacture's protocol description. Total calcium was calculated from standard curves of solutions prepared in parallel with the experiments and expressed as $\mu \mathrm{g} \mathrm{Ca} / \mu \mathrm{g} \mathrm{DNA}$.

\section{Two-dimensional gel electrophoresis and silver staining}

Six serum samples from PB or BMA for proteomic analysis were collected. To improve the performance of the analysis of the serum samples, albumin and immunoglobulin G in the collected serum samples were depleted using an albumin and IgG removal kit (Depletion Spin Trap, GE

PB

BMA
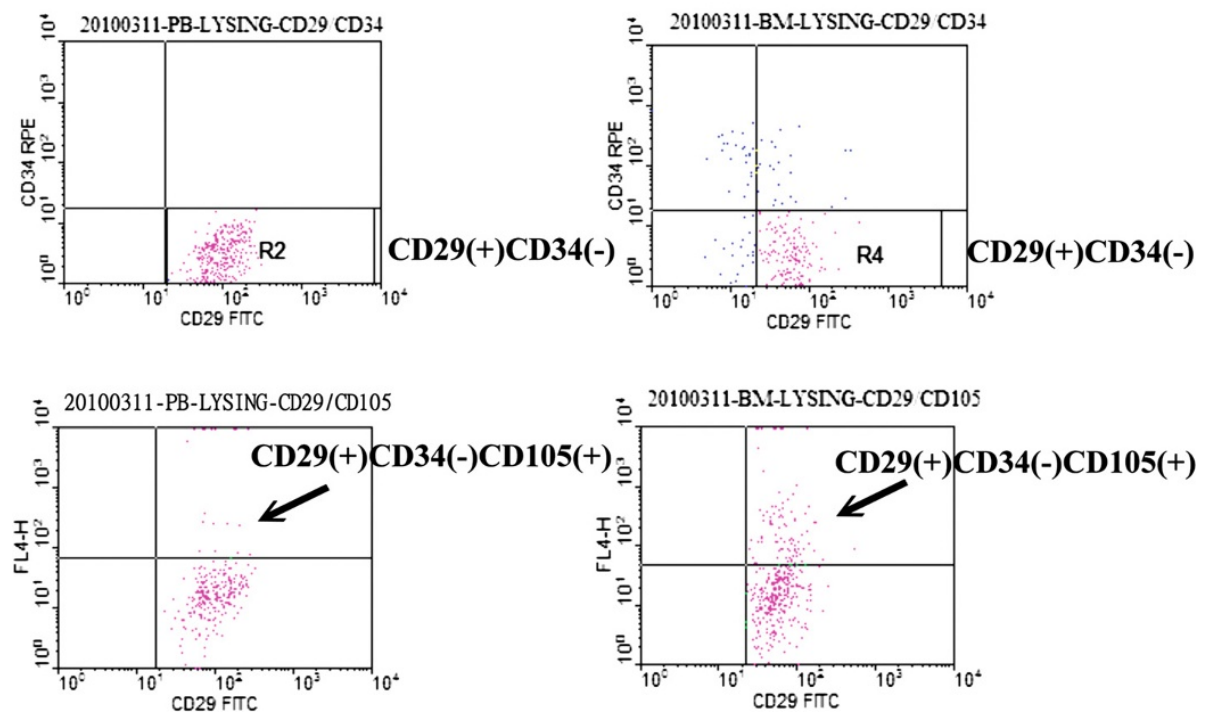

Figure 1 Flow cytometry analysis of MSC-like cells from PB and BMA. The proportion of CD34- $/ \mathrm{CD} 29^{+} / \mathrm{CD} 105^{+}$-nucleated cells in the PB was significantly lower than that in the BMA ( $t$ test, $p<0.01, n=4)$. 


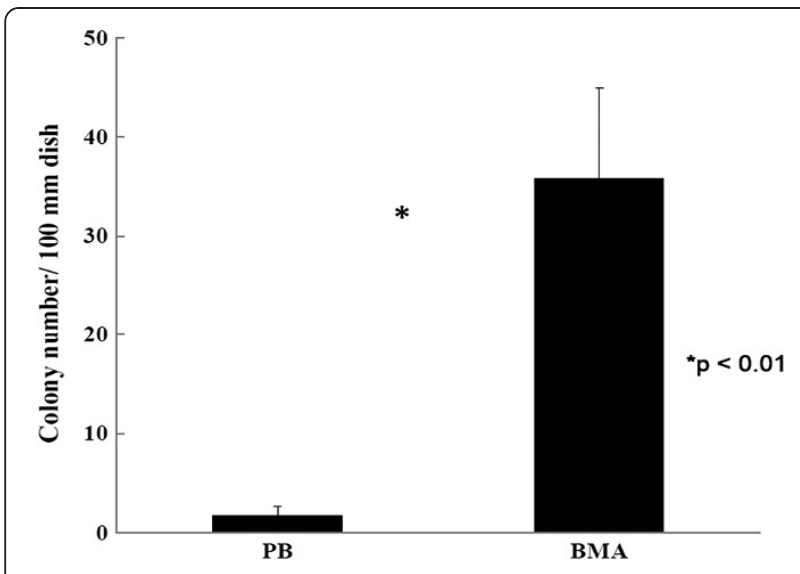

Figure 2 Fibroblast-colony-forming units (CFU-F) assay. Fewer colonies were formed in the PB cultures than in BMA cultures ( $t$ test, $p<0.01, n=4)$.

Healthcare UK Limited, Amersham, Buckinghamshire, UK) according to the manufacturer's instructions. The procedures for 2-DE gel running, staining, and imaging were as previously described [17-19]. Briefly, aliquots in sample buffer (7 M urea, $2 \mathrm{M}$ thiourea, 4.5\% CHAPS, $100 \mathrm{mM}$ DTE, $40 \mathrm{mM}$ Tris, $\mathrm{pH}$ 8.8) were applied to immobilized $\mathrm{pH} 3$ to 10 nonlinear gradient strips (Amersham Biosciences, Uppsala, Sweden). IEF was performed at $80,000 \mathrm{Vh}$. The second dimension was analyzed on $9 \%$ to $16 \%$ linear gradient polyacrylamide gels at constant $40 \mathrm{~mA}$ per gel for approximately $5 \mathrm{~h}$. Proteins resolved by 2-DE were visualized by silver staining as previously described [17-19]. Briefly, the gels were fixed in $30 \%$ methanol for $15 \mathrm{~min}$ and then subjected to washing with water, followed by $2 \mathrm{~min}$ in sodium thiosulfate $(0.8 \mathrm{mM})$, then washing again with water and subsequently equilibrated with $0.2 \% \mathrm{w} / v$ silver nitrate for $25 \mathrm{~min}$. The gels were then rinsed three times with water and developed in $3 \%$ sodium carbonate containing $0.04 \% v / v$ formaldehyde (37\% solution). The reaction was stopped with $40 \mathrm{mM}$ EDTA and the gels were washed three times with water. Finally, the gels were scanned and the images analyzed using Image Master 2D software, version 4.01.

\section{In-gel digestion of proteins and mass spectrometric analysis}

More than 1.5-fold increased or decreased silverstained spots were excised and in-gel digested with trypsin according to procedures described previously [17-19]. Briefly, the gels were destained by $1 \%$ potassium ferricyanide and $1.6 \%$ sodium thiosulfate (Sigma, St. Louis, MO, USA). The proteins were then reduced with $25 \mathrm{mM} \mathrm{NH}_{4} \mathrm{HCO}_{3}$ containing $10 \mathrm{mM}$ DTT (Biosynth, Switzerland) at $60^{\circ} \mathrm{C}$ for $30 \mathrm{~min}$ and alkylated with $55 \mathrm{mM}$ iodoacetamide (Amersham Biosciences, Amersham, Buckinghamshire, UK) at room temperature for $30 \mathrm{~min}$. After reduction and alkylation, the proteins were digested with trypsin (Promega, Madison, WI, USA) $(20 \mathrm{mg} / \mathrm{ml})$ at $37^{\circ} \mathrm{C}$ overnight. After digestion, the tryptic peptides were acidified with $0.5 \%$ TCA and loaded onto an MTP Anchor Chip $^{\text {тм }}$ 600/384 TF (Bruker Daltonik GmbH, Bremen, Germany). MALDI-TOF MS analysis was performed on an Ultraflex ${ }^{\text {TM }}$ MALDI-TOF mass spectrometer (Bruker Daltonik). Mono-isotopic peptide masses were assigned and used for database searches with the MASCOT search engine (http://www.matrixscience.com) (Matrix Science, London, UK).

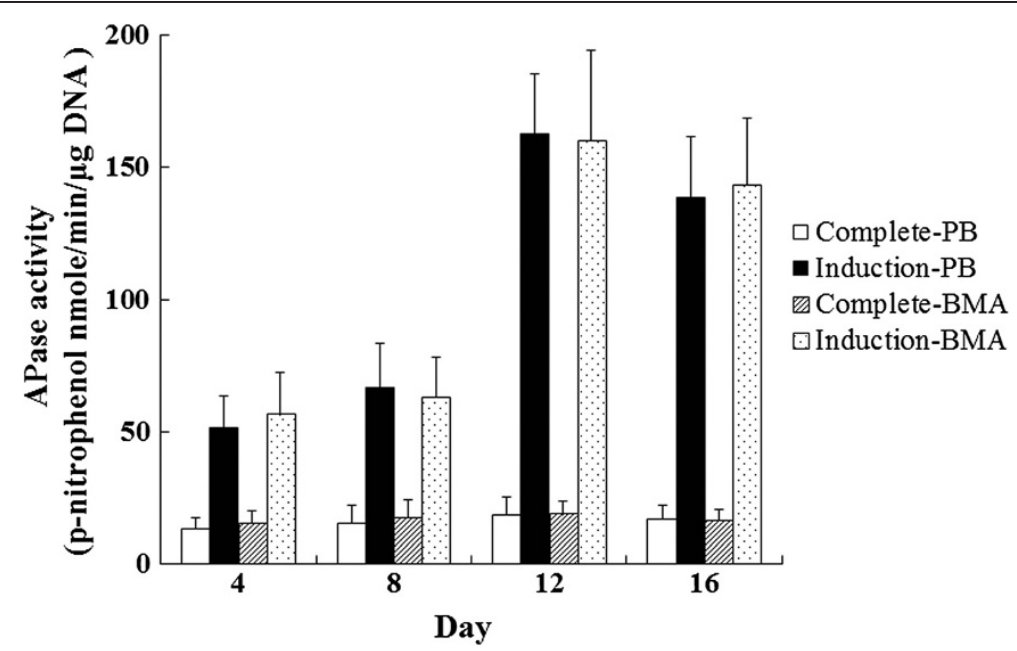

Figure 3 Alkaline phosphatase (ALP) activity measurement. There was higher ALP activity in the induction medium culture than in the complete medium culture in both PB and BMA ( $t$ test, $p<0.01, n=3$ ). There were no significant differences in ALP activity between the PB and BMA in complete medium or induction medium culture in each time point shown $(t$ test, $p>0.05, n=3)$. 


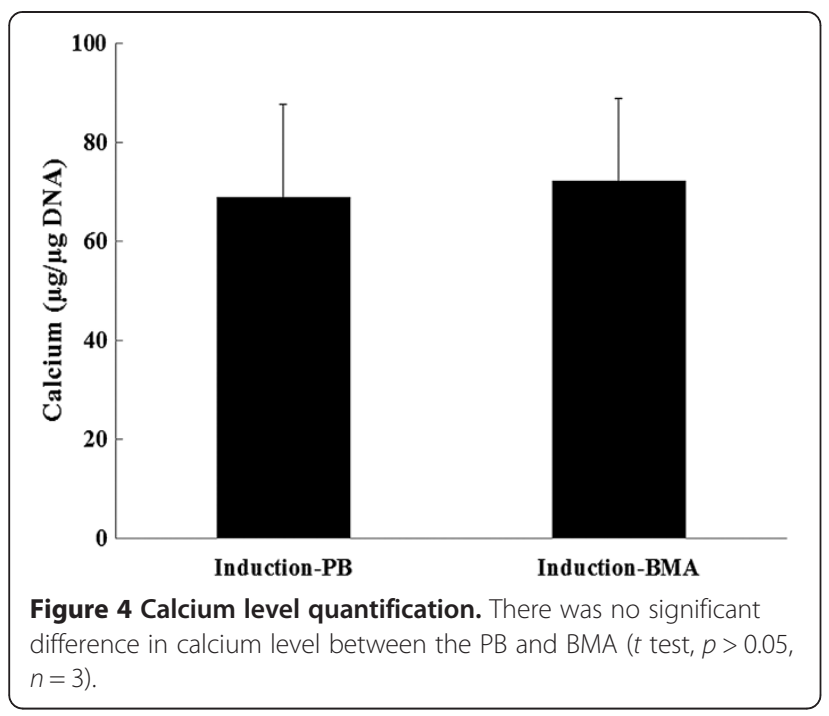

Western blot analysis

Twelve serum samples from PB or BMA were collected for Western blotting. The protein content was quantitated using a protein assay kit (Pierce Biotechnology, Rockford, IL, USA), separated by $6 \%$ SDS-PAGE for catalase and $10 \%$ for glutathione peroxidase and $\beta$-actin, and transferred onto membranes using a transfer unit (Bio-Rad, Hercules, CA, USA). After blocking, the membranes were incubated with 1,000-fold diluted rabbit antibodies against catalase and glutathione peroxidase (Abcam, Cambridge, UK) or mouse antibodies against $\beta$-actin (Millipore, Temecula, CA, USA). After washing, the membranes were further incubated for $2 \mathrm{~h}$ with 10,000-fold goat anti-mouse IgG (Calbiochem, Millipore, Billerica, MA, USA) or goat anti-rabbit IgG (Millipore) conjugated to horseradish peroxidase. The membranes were then washed and rinsed with ECL detection reagents (Amersham Pharmacia Biotech, Amersham, Buckinghamshire, UK). The band images were photographed using ECL Hyperfilm (Amersham).

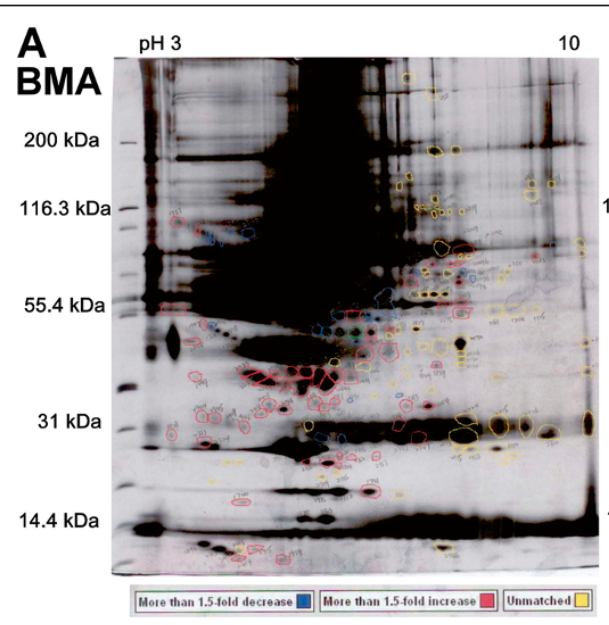

B catabse
BMA
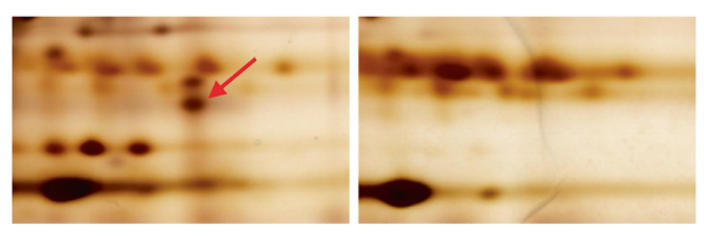

PB

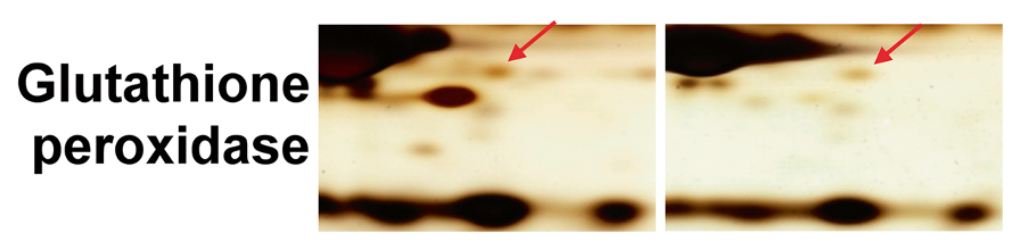

Figure 5 Protein profiling of BMA and PB specimens. (A) Proteins (150 mg) were subjected to 2-DE (pH 3 to 10) and detected by silver staining. Spots that had more than a 1.5-fold increase or decrease in silver staining were excised and in-gel digested with trypsin. At least 11 protein spots were detected at higher expression levels and 5 at lower expression levels in the BMA than in the PB. (B) Cropped images showing the two selected proteins (catalase and Gpx) from 2-D gels. 
Table 2 2-DE and MALDI-TOF MS identification of proteins that are differentially expressed in BMA and PB

\begin{tabular}{|c|c|c|c|c|c|c|}
\hline Spot & Protein name & $\mathrm{Mr}$ & $\mathrm{pl}$ & Score $^{a}$ & Sequence coverage $^{\mathbf{b}}(\%)$ & Trend \\
\hline 1 & Hemoglobin subunit beta & 16,102 & 6.75 & 68 & 57 & $B M A>P B$ \\
\hline 2 & Catalase & 59,947 & 6.9 & 206 & 53 & $B M A>P B$ \\
\hline 3 & Ferritin light chain & 20,064 & 5.51 & 142 & 63 & $\mathrm{BMA}>\mathrm{PB}$ \\
\hline 4 & Flavin reductase & 22,219 & 7.13 & 179 & 89 & $\mathrm{BMA}>\mathrm{PB}$ \\
\hline 5 & Protein S100-A8 & 10,885 & 6.51 & 103 & 67 & $\mathrm{BMA}>\mathrm{PB}$ \\
\hline 6 & Complement C3 & 188,569 & 6.02 & 66 & 11 & $\mathrm{BMA}>\mathrm{PB}$ \\
\hline 7 & Fibrinogen beta chain & 56,577 & 8.54 & 148 & 51 & $B M A>P B$ \\
\hline 8 & Hemopexin & 52,385 & 6.55 & 121 & 41 & $\mathrm{BMA}<\mathrm{PB}$ \\
\hline 9 & Serotransferrin & 79,280 & 6.81 & 92 & 25 & $\mathrm{BMA}<\mathrm{PB}$ \\
\hline 10 & Transthyretin & 15,991 & 5.52 & 155 & 73 & $\mathrm{BMA}>\mathrm{PB}$ \\
\hline 11 & Clusterin & 53,031 & 5.89 & 108 & 41 & $\mathrm{BMA}>\mathrm{PB}$ \\
\hline 12 & Apolipoprotein A-I & 30,759 & 5.56 & 113 & 49 & $\mathrm{BMA}<\mathrm{PB}$ \\
\hline 13 & Peroxiredoxin-2 & 22,049 & 5.66 & 181 & 72 & $\mathrm{BMA}>\mathrm{PB}$ \\
\hline 14 & Leucine-rich alpha-2-glycoprotein & 38,382 & 6.45 & 89 & 42 & $\mathrm{BMA}<\mathrm{PB}$ \\
\hline 15 & Fibrinogen gamma chain & 52,106 & 5.37 & 131 & 48 & $\mathrm{BMA}<\mathrm{PB}$ \\
\hline 16 & Glutathione peroxidase & 25,765 & 8.26 & 67 & 39 & $\mathrm{BMA}>\mathrm{PB}$ \\
\hline
\end{tabular}

${ }^{a}$ The MASCOT search score of identified proteins is shown; ${ }^{b}$ the percentage of sequence coverage (Seq Cov) of matched peptides in the identified protein.

\section{Results}

\section{MSCs (CD34 $\left.{ }^{-} / \mathrm{CD}^{2} 9^{+} / \mathrm{CD} 105^{+}\right)$isolated from PB and BMA}

The proportion of $\mathrm{CD} 34^{-} / \mathrm{CD} 29^{+} / \mathrm{CD} 105^{+}$-nucleated cells in the PB was significantly lower than that in the BMA (Figure $1,0.06 \% \pm 0.03 \%$ vs. $0.24 \% \pm 0.06 \%, p<0.01, n=4$ ).

\section{Colony-forming units assay}

To determine the clonogenic potential of MSCs, colonyforming units (CFU-F) assays were performed after 2 weeks of culture. The mean colony-forming efficiency was $1.8 \pm 0.9$ mononuclear cells for the PB and $35.8 \pm 9.1$ mononuclear cells for the BMA. Fewer colonies were formed in the $\mathrm{PB}$ cultures than in the BMA cultures (Figure 2, $p<0.01, n=4$ ).

\section{Alkaline phosphatase activity measurement}

For the PB group, alkaline phosphatase (ALP) activity measured in the complete medium was $13.2 \pm 4.1,15.1 \pm$ 7.2, $18.3 \pm 6.7$, and $17.1 \pm 5.1 \mathrm{nmol} p$-nitrophenol $/ \mathrm{min} /$ $\mu \mathrm{g}$ DNA after $4,8,12$, and 16 days, respectively. ALP activity measured in the induction medium was $51.5 \pm$ $12.2, \quad 66.5 \pm 17.2, \quad 162.7 \pm 22.4$, and $138.3 \pm 23.5 \mathrm{nmol}$ $p$-nitrophenol $/ \mathrm{min} / \mu \mathrm{g}$ DNA after $4,8,12$, and 16 days, respectively. There was higher ALP activity in the induction medium than in complete medium culture in each time point showed (Figure 3, $p<0.01, n=3$ ).

For the BMA group, ALP activity measured in the complete medium was $15.2 \pm 5.1,17.2 \pm 6.9,18.6 \pm 5.2$, and $16.4 \pm 4.3 \mathrm{nmol} p$-nitrophenol $/ \mathrm{min} / \mu \mathrm{g}$ DNA after 4 ,
8,12 , and 16 days, respectively. ALP activity measured in the induction medium was $56.5 \pm 16.2,62.9 \pm 115.4$, $160.1 \pm 33.9$, and $143.2 \pm 25.2 \mathrm{nmol} p$-nitrophenol $/ \mathrm{min} /$ $\mu \mathrm{g}$ DNA after $4,8,12$, and16 days, respectively. There was higher ALP activity in the induction medium than in the complete medium culture at each time point (Figure 3, $p<0.01, n=3$ ). However, there was no significant difference between the PB and BMA in complete medium or induction medium culture in each time point showed (Figure 3, $p>0.05, n=3)$.

\section{Calcium level quantification}

The calcium level was $69 \pm 18.5 \mu \mathrm{g} \mathrm{Ca} / \mu \mathrm{g}$ DNA for the $\mathrm{PB}$ group and $72.3 \pm 16.4 \mu \mathrm{g} \mathrm{Ca} / \mu \mathrm{g}$ DNA for the BMA group. There was no significant difference between the $\mathrm{PB}$ and BMA in calcium level (Figure 4, $p>0.05, n=3$ ).

\section{Protein profiles of BMA and paired PB}

In the proteins extracted from the paired specimens, at least 11 protein spots were detected at higher expression levels and 5 at lower expression levels in the BMA than in the PB (Figure 5a). MALDI-TOF MS was used to identify the proteins corresponding to these 16 spots, and the relative levels of these proteins between the BMA and $\mathrm{PB}$ were quantitated by image analysis (Table 2). Although other spots also showed different intensities between the BMA and $\mathrm{PB}$ in 2-DE, they could not be definitively identified by MS. We thus focused on the 16 spots that showed differences in intensity and could be unequivocally identified by MS. At 


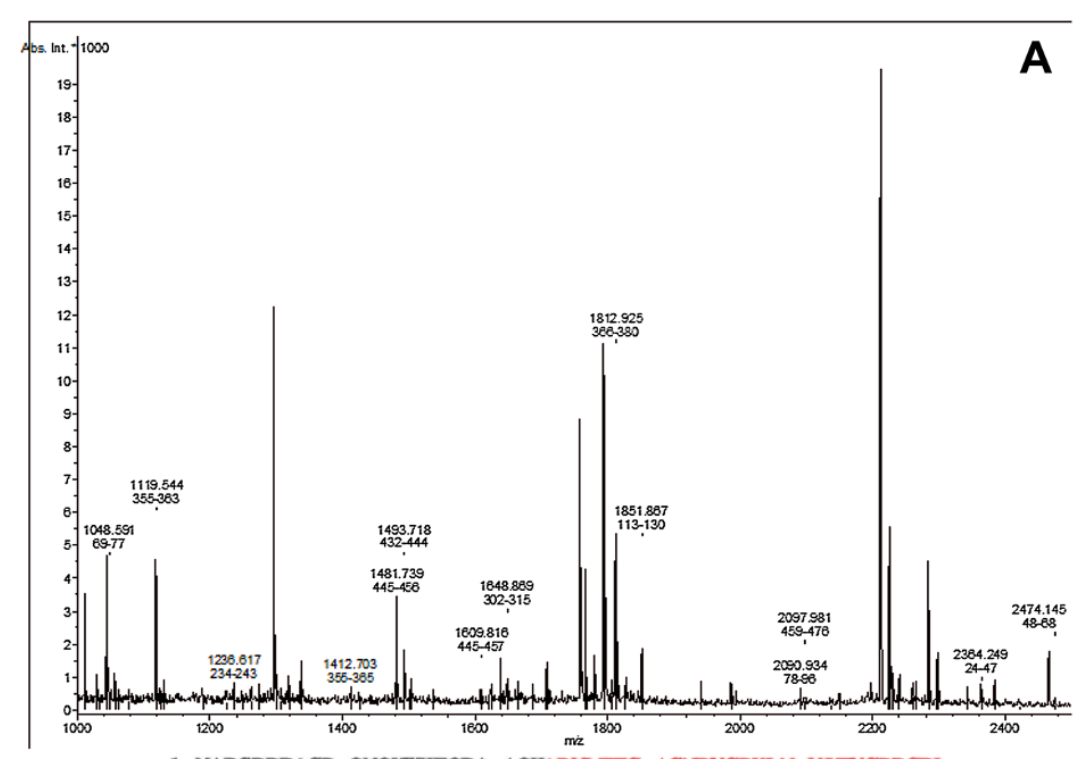

1 MADSRDPASD QMQHWKEQRA AQKADVLTTG AGNPVGDKLN VITVGPRGPL

51 LVODVVFTDE MAHFDRERIP ERVVHAKGAG AFGYFEVTHD ITKYSKAKVF

101 EHIGKKTPIA VRFSTVAGES GSADTVRDPR GFAVKFYTED GNWDLVGNT

151 PIFFIRDPIL FPSFIHSQKR NPQTHLKDPD MVWDFWSLRP ESLHQVSFLF

201 SDRGIPDGHR HMNGYGSHTF KLVNANGEAV YCKFHYKTDO GIKNLSVEDA

251 ARLSQEDPDY GIRDLFNAIA TGKYPSWTFY IQVMTFNQAE TFPFNPFDLT

301 KVWPHKDYPL IPVGKLVLNR NPVNYFAEVE QIAFDPSNMP PGIEASPDKM

351 LQGRLFAYPD THRHRLGPNY LHIPVNCPYR ARVANYQRDG PMCMQDNQGG

401 APNYYPNSFG APEQQPSALE HSIQYSGEVR RFNTANDDNV TOVRAFYVNV

451 LNEEORKRLC ENIAGHLKDA OIFIOKKAVK NFTEVHPDYG SHIQALLDKY

501 NAEKPKNAIH TFVQSGSHLA AREXANL

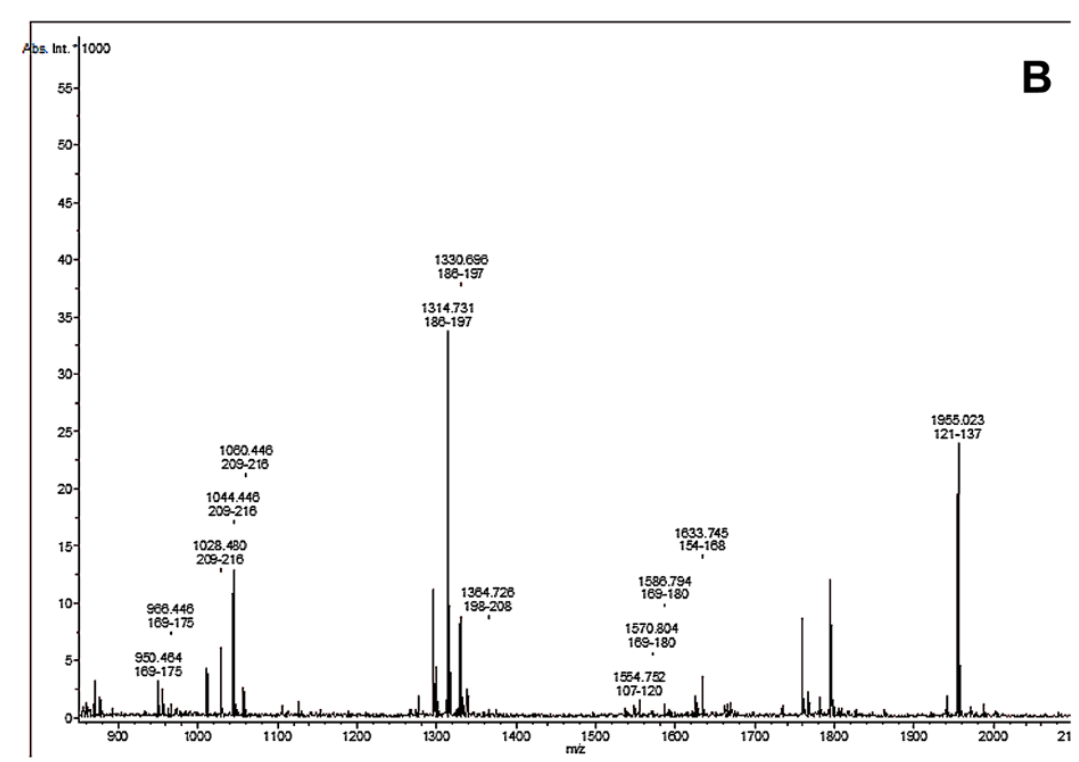

1 MARLLOASCL LSLULAGFVS QSRGQEKSKM DCHGGISGTI YEYGALTIDG 51 EEYIPFKQYA GKYVLFVNVA SYUGLTGQYI ELNALQEELA PFGLVILGFP 101 ONQFGKOEPG ENSEILPTLK YVRPGGGFVP NFOLFEKGDV NGEKEOKFYT 151 FLKNSCPPTS ELLLTSDDRLF FEPMKVHDIR RNFEKFLVGP DGIPIMRWHH 201 RTTVSNVKMD ILSYMRRQAA LGVKRK

Figure 6 Mass spectrometric analysis of the protein spots. Protein spots of catalase (A) and Gpx (B) were picked, in-gel digested with trypsin, and analyzed by MALDITOF MS. The matched peptides from mass spectrometric analysis of both spots to the amino acid sequence of human catalase and Gpx are underlined and in bold. 


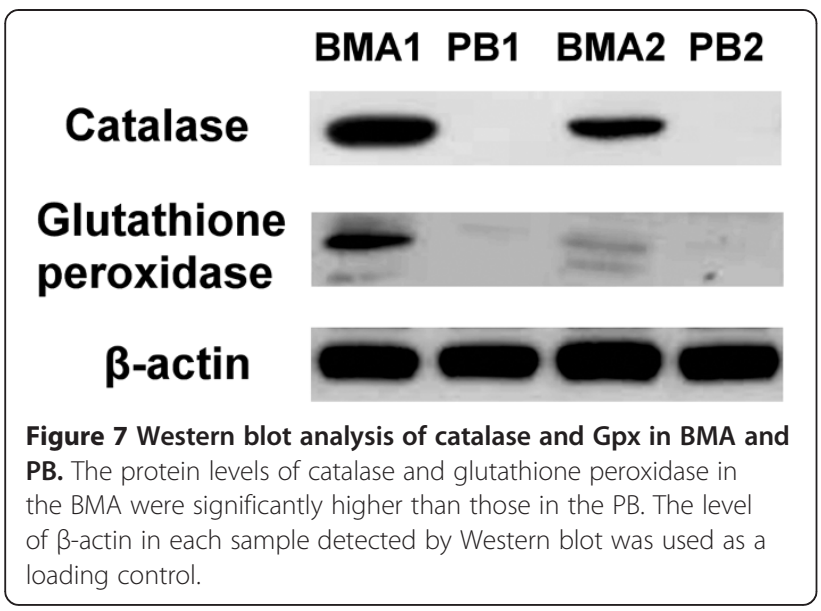

least two osteogenesis-related proteins were found, and there were higher catalase (osteoclast inhibitor) and glutathione peroxidase 3 (osteogeneic biomarker) content in the BMA than in the PB (Figure 5b). The identities of these two protein spots were confirmed by MALDI-TOF MS and shown in Figure 6.

\section{Western blot analysis of proteins expression in BMA and PB} To confirm the data obtained from 2-DE analysis, the serum was detected by Western blotting with specific antibodies. Our results revealed that the protein levels of catalase and glutathione peroxidase in the BMA were significantly higher than those in the PB (Figure 7).

\section{Discussion}

Morphologically, no specific characteristics distinguish MSCs from other nucleated cells within BMA or PB. To distinguish MSCs, specific markers reacting with cell receptor sites instead must be identified. Specific monoclonal antibodies react with molecules on specific cell surfaces and can be used to identify the protein clusters for the markers which can facilitate the identification, isolation, and study of stem cells. Multiple surface markers have been associated with stem cells including CD29, CD34, CD106, CD105, and CD309 (KDR) [20-22].

The use of FACS has the potential to identify MSCs more precisely. CD29 and CD105 are expressed by MSCs [11,23] whereas CD34 is expressed by hematopoietic stem cells and capillary endothelial progenitor cells but not MSCs $[11,20,23]$. In the present study, the results suggested that the proportion of MSC-like cells $\left(\mathrm{CD} 34^{-} / \mathrm{CD} 29^{+} / \mathrm{CD} 105^{+}\right)$ in the $\mathrm{PB}$ was significantly lower than that in the BMA, which provides quantified information for the osteopromotive effects of BMA (Figure 1). In addition, CFU-F assays also suggested that fewer colonies were formed in the $\mathrm{PB}$ cultures than in BMA cultures (Figure 2). CFU-Fs are clearly indicative of cells capable of forming colonies and are representative of the more highly proliferative cells in these cultures [21]. Under proper experimental conditions, BMA CFU-Fs are able to differentiate into bone, cartilage, adipocytes, fibrous tissues, and hematopoietic supporting tissues in vitro and in vivo [11,22]. In the present study, the osteogenic potential of CFU-Fs was determined by ALP activity (Figure 3 ) and calcium level (Figure 4), and no significant differences between the $\mathrm{PB}$ and BMA were found. Although, fewer colonies were formed in the PB cultures than in BMA cultures (Figure 2), the CFU-Fs isolated from these two groups had similar proliferation and differentiation abilities.

Connolly et al. [24] clinically found the osteopromotive effects of whole bone marrow when autologous marrow was injected into a tibial defect site. Although both blood and bone marrow can be immediately harvested and used as autologous materials for osteopromotion, an in vivo animal study [9] showed that BMA has a higher osteogenic potential than blood when it is impregnated through $\beta$-tricalcium phosphate $(\beta$-TCP), an osteoconductive scaffold. The authors have previously reported on the use of BMA in combination with the scaffold material at grafting sites and indicated that BMA augments spinal arthrodesis [10]. The reason for this difference may be the proportion of bone marrow MSCs in BMA.

To find possible factors to gain new insight into the mechanisms of bone formation and development, we subjected proteins extracted from BMA specimens and paired $\mathrm{PB}$ to 2-DE separation, silver staining, and MALDI-TOF MS analysis (Figures 5 and 6). At least two osteogenesis related proteins were found: there were higher catalase and glutathione peroxidase 3 (Gpx 3) content in the BMA than in the PB. The protein level of catalase was significantly up-regulated in a time-dependent manner during osteogenic differentiation thus reduce the excess reactive oxygen species (ROS) production to hamper the osteogenic differentiation of MSCs [25]. In addition, catalase has been reported to partially inhibit ascorbic acid-induced osteoclastogenesis [26]. Selenite enhanced the gene expression and activity of Gpx, reversed the decreased total antioxidant capacity and reduced glutathione, and against hydrogen peroxide-induced inhibition of osteoblastic differentiation of MSCs [27].

Aspiration of autogenous bone marrow cells from the iliac crest is a simple and safe procedure that can be performed with the patient under anesthesia and involves little to no donor site morbidity. The use of such material at bone-grafting sites has the potential to produce a significant quantity of viable bone $[10,28]$. BMA may have the ability to facilitate osteogenesis by acting as both an osteoprogenitor and osteoinductor to supplement the limited amount of available autologous bone for multilevel spinal fusion. 
In the present study, the proportions of MSCs and osteogenic factors were higher in the BMA than in the PB. This may explain why fusion rate can be augmented by BMA in lumbar posterolateral fusion. In the future, we will evaluate whether the fusion rate of autogenous laminectomy bone chips could be augmented by BMA in a rabbit model.

\section{Conclusion}

The proportions of MSCs and osteogenic factors were higher in the BMA than those in the PB. This may explain why fusion rate can be augmented by BMA in lumbar posterolateral fusion.

\section{Competing interests}

The authors declare that they have no competing interests.

\section{Authors' contributions}

NCC, LSS, and CWJ did the study design. YLJ and YCY analyzed and interpreted the data. NCC, CYS, and CWJ provided the study material or patients. PTL, LPL, and CLH drafted the manuscript. All authors read and approved the final version of the manuscript.

\section{Acknowledgements}

We thank the technical support by Proteomics Core Lab of Chang Gung University. This research was supported by grants from the Chang Gung Memorial Hospital, Taiwan, Republic of China (CMRPG380771).

\section{Author details}

'Department of Orthopaedic Surgery, Chang Gung Memorial Hospital, No 5, Fu-Hsing Street 333, Taoyuan, Kweishan, Taiwan. ${ }^{2}$ Graduate Institutes of Biomedical Sciences, Chang Gung University, Taoyuan, Taiwan. ${ }^{3}$ School of Traditional Chinese Medicine, Chang Gung University, Taoyuan, Taiwan. ${ }^{4}$ Research Center for Industry of Human Ecology, Chang Gung University of Science and Technology, Taoyuan, Taiwan. ${ }^{5}$ College of Medicine, Chang Gung University, Taoyuan, Taiwan.

Received: 7 February 2014 Accepted: 21 April 2014

Published: 3 May 2014

\section{References}

1. Nather A: Use of allograft in spinal surgery. Ann Transp/ 1999, 4:19-22.

2. Gibson S, McLeod I, Wardlaw D, Urbaniak S: Allograft versus autograft in instrumented posterolateral lumbar spinal fusion: a randomized control trial. Spine 2002, 27:1599-1603.

3. Baramki HG, Steffen T, Lander P, Chang M, Marchesi D: The efficacy of interconnected porous hydroxyapatite in achieving posterolateral lumbar fusion in sheep. Spine 2000, 25:1053-1060.

4. Chen WJ, Tsai TT, Chen LH, Niu CC, Lai PL, Fu TS: The fusion rate of calcium sulfate with local autograft bone compared with autologous iliac bone graft for instrumented short-segment spinal fusion. Spine 2005, 30:2293-2297

5. Louis-Ugbo J, Murakami H, Kim HS, Minamide A, Boden SD: Evidence of osteoinduction by Grafton demineralized bone matrix in nonhuman primate spinal fusion. Spine 2004, 29:360-366.

6. Cammisa FP Jr, Lowery G, Garfin SR, Geisler FH, Klara PM, McGuire RA, Sassard WR, Stubbs H, Block JE: Two-year fusion rate equivalency between Grft on DBM gel and autograft in posterolateral spine fusion: a prospective controlled trial employing a side-by-side comparison in the same patient. Spine 2004, 29:660-666

7. Tay BK, Le AX, Heilman M, Lotz J, Bradford DS: Use of a collagen-hydroxyapatite matrix in spinal fusion: a rabbit model. Spine 1998, 23:2276-2281.

8. Muschler GF, Nitto H, Matsukura Y, Boehm C, Valdevit A, Kambic H, Davros W, Powell K, Easley K: Spine fusion using cell matrix composites enriched in bone marrow-derived cells. Clin Orthop 2003, 407:102-118.
9. Becker S, Maissen O, Igor P, Thierry S, Rahn B, Ingo W: Osteopromotion by a $\beta$-tricalcium phosphate/bone marrow hybrid implant for use in spine surgery. Spine 2006, 31:11-17.

10. Niu CC, Tsai TT, Fu TS, Lai PL, Chen LH, Chen WJ: A comparison of posterolateral lumbar fusion comparing autograft, autogenous laminectomy bone with bone marrow aspirate, and calcium sulphate with bone marrow aspirate. Spine 2009, 34:2715-2719.

11. Pittenger MF, Mackay AM, Beck SC, Jaiswal RK, Douglas R, Mosca JD, Moorman MA, Simonetti DW, Craiq S, Marshak DR: Multilineage potential of adult human mesenchymal stem cells. Science 1999, 284:143-147.

12. Dominici M, Le Blanc K, Mueller I, Slaper-Cortenbach I, Marini F, Krause D, Deans R, Keating A, Prockop D, Horwitz E: Minimal criteria for defining multipotent mesenchymal stromal cells: the international society for cellular therapy position statement. Cytotherapy 2006, 8:315-317.

13. Ardekani AM, Liotta LA, Petricoin EF III: Clinical potential of proteomics in the diagnosis of ovarian cancer. Expert Rev Mol Diagn 2002, 2:312-320.

14. Anderson NL, Anderson NG: The human plasma proteome: history, character, and diagnostic prospects. Mol Cell Proteomics 2002, 1:845-867.

15. Li C, Tan YX, Zhou H, Ding SJ, Li SJ, Ma DJ, Man XB, Hong Y, Zhang L, Li L, Xia QC, Wu JR, Wang HY, Zeng R: Proteomic analysis of hepatitis B virus-associated hepatocellular carcinoma: identification of potential tumor markers. Proteomics 2005, 5:1125-1139.

16. He QY, Cheung YH, Leung SY, Yuen ST, Chu KM, Chiu JF: Diverse proteomic alterations in gastric adenocarcinoma. Proteomics 2004, 4:3276-3287.

17. Wu CC, Chien KY, Tsang NM, Chang KP, Hao SP, Tsao CH, Chang YS, Yu JS: Cancer cell-secreted proteomes as a basis for searching potential tumor markers: nasopharyngeal carcinoma as a model. Proteomics 2005, 5:3173-3182.

18. Hwang TL, Liang Y, Chien KY, Yu JS: Overexpression and elevated serum levels of phosphoglycerate kinase 1 in pancreatic ductal adenocarcinoma. Proteomics 2006, 6:2259-2272.

19. Cho SY, Lee EY, Lee JS, Kim HY, Park JM, Kwon MS, Park YK, Lee HJ, Kang MJ, Kim JY, Yoo JS, Park SJ, Cho JW, Kim HS, Paik YK: Efficient prefractionation of low-abundance proteins in human plasma and construction of a two-dimensional map. Proteomics 2005, 5:3386-3396.

20. Steen R, Egeland T: CD34 molecule epitope distribution on cells of hematopoietic origin. Leuk Lymphoma 1998, 30:23-30.

21. D'lppolito G, Schiller PC, Ricordi C, Roos BA, Howard GA: Age-related osteogenic potential of mesenchymal stromal stem cells from human vertebral bone marrow. J Bone Miner Res 1999, 14:1115-1122.

22. Jiang $Y$, Jahagirdar $B N$, Reinhardt RL, Schwartz RE, Keene CD, Ortiz-Gonzalez XR, Reyes M, Lenvik T, Lund T, Blackstad M, Du J, Aldrich S, Lisberg A, Low WC, Largaespada DA, Verfaillie CM: Pluripotency of mesenchymal stem cells derived from adult marrow. Nature 2002, 418:41-49.

23. Smiler D, Soltan M, Albitar M: Toward the identification of mesenchymal stem cells in bone marrow and peripheral blood for bone regeneration. Implant Dent 2008, 17:236-247.

24. Connolly JF, Guse R, Tiedeman J, Dehne R: Bone marrow injection as a substitute for operative grafting of tibial nonunions. Clin Orthop 1991, 266:259-270.

25. Chen CT, Shih YRV, Kuo TK, Lee OK, Wei YH: Coordinated changes of mitochondrial biogenesis and antioxidant enzymes during osteogenic differentiation of human mesenchymal stem cells. Stem Cells 2008, 26:960-968.

26. Nihouannen DE, Barralet JE, Fong JE, Komarova SV: Ascorbic acid accelerates osteoclast formation and death. Bone 2010, 46:1336-1343.

27. Liu H, Bian W, Liu S, Huang K: Selenium protects bone marrow stromal cells against hydrogen peroxide-induced inhibition of osteoblastic differentiation by suppressing oxidative stress and ERK signaling pathway. Biol Trace Elem Res 2012, 150:441-450.

28. Smiler D, Soltan M: A histomorphogenic analysis of bone grafts augmented with adult stem cells. Implant Dent 2007, 16:42-47.

doi:10.1186/1749-799X-9-32

Cite this article as: Niu et al:: Identification of mesenchymal stem cells and osteogenic factors in bone marrow aspirate and peripheral blood for spinal fusion by flow cytometry and proteomic analysis. Journal of Orthopaedic Surgery and Research 2014 9:32. 